\title{
A new optimization-simulation model considering sustainability factors in the product design
}

DOI:10.36909/jer.13503

\author{
Elahe Mohagheghian, Hasan Hosseini-Nasab*, Yahia Zare-Mehrjerdi \\ Department of industrial engineering, Yazd University, Yazd, Iran. \\ *Email: hosseininasb@gmail.com; Corresponding Author.
}

\begin{abstract}
This study aims at understanding factors of an industrial product driving the sustainability and long-term survival. On the whole, sustainability in product design is an important issue for attracting and retaining customers around the world. Based on a printer case, this study attempted to determine sustainability factors in the product design based on a hybrid method of the conjoint analysis (CA), the fuzzy cognitive mapping (FCM) and the system dynamics (SD). In this approach, first, the optimal values of initial data are determined by $\mathrm{CA}$. These values are entered into a FCM-SD model to evaluate the cause-and-effect relationships between factors of sustainability and long term scenarios. The results provide insights into which factors most strongly influence sustainability, namely, environmental, social, and economical factors. Hence, diverse scenarios at inter and intra-cluster levels were created to clarify the effects of variable changes on the model described.
\end{abstract}

Key words: Sustainability; Conjoint analysis (CA); System dynamics (SD); Fuzzy cognitive maps (FCM); Product design.

\section{INTRODUCTION}

In the last decade, sustainability has become an important issue for attracting and retaining customers; manufacturers have been emphasizing on integrating environmental, (e.g., environmental impacts, and lifespan factors) and social (e.g., reliability and transparency issues) goals in addition to economic (e.g., manufacturing, advertising, recovering costs) concerns during the design process. A sustainable design affects all parts of the society, hence, taking into account the issue of sustainability is very essential for the overall society.

In fact, Sustainable design is a complicated issue with many identifying factors to presume. The models provided in the literature on the scope of sustainable product design reveal some drawbacks related to the data, and variables required as well as their corresponding cause-andeffect relationships. Researchers cannot comprehend integrated the dynamics of the sustainability factors through analyses of the results of changes in these factors. Given these drawbacks, this study tried to investigate the important factors by using conjoint analysis (CA), fuzzy cognitive mapping (FCM) and the system dynamics (SD) approach. There have been comparatively few studies which investigated the presented hybrid approach in this paper, so the mentioned methodology contributes to the literature on design and sustainability science. The data needed for the SD were gathered from CA, and then their cause-and-effect relationships were portrayed, in order to conduct the FCM and SD analyses. To identify the long-term results of changes in the variables, the provided information allowed for the specifying four scenarios with eight simulations. 


\section{RESEARCH BACKGROUND AND LITERATURE REVIEW}

\section{Background}

\section{a. Fuzzy cognitive mapping}

In practice, the phrase cognitive map based on (Abramova, 2016), 'refers to models, visualizing the structure of causal influences of systems'. This description primarily originate from the method that the cognitive maps are a representation of relationships between the model variables. These maps are a combination of arrows and nodes, so that the direction of the arrows visualized the causality between criteria. The fuzzy cognitive maps (FCMs) was first examined by (Kosko, 1986). The fuzzy logic of these maps is that how cause-and-effect relationships and their criteria can explicate real values. The major difference between FCMs and cognitive maps is the way of visualization of cause-and-effect relationships. FCMs implement a minus (-) or plus (+) sign and a value termed as "weight". The weights ranges vary from 0 to 1 or -1 to +1 , depending on the diverse types of the cause-and effect relationships among concepts.

\section{b. Conjoint analysis}

CA is applied specifically to determine consumer's attitudes towards the products. This methodology can help study the market of many industrial products (Green \& Srinivasan, 1978). A fundamental idea in the CA is that a product can be broken down into a collection of relevant attributes. For example, a printer has attributes such as price, speed of print, print quality, recoverable materials, reliability, etc.

\section{c. Profit maximization}

The total value of profit, $\pi$ is obtained by multiplying the profit per unit of a product by the market demand, $Q$. Therefore, we have:

$$
\pi=(p r-c) Q
$$

Optimizers can consider gradient-based algorithms such as sequential quadratic programming (SQP) to solve such nonlinear problems. However, these methods suffer from shortcomings such as computational complexity, and local minimum traps. This has created the need for developing a new type of solution that can address these drawbacks. Using a derivation-free global search algorithm (DFGS) can overcome most of the limitations associated with gradient-based methods (Papalambros \& Wilde, 2000).

\section{d. System dynamics}

SD is a concept was first introduced by (Forrester, 1958) and since then have been widely applied for different supply chains. To simulate SD continuously, we should estimate mathematical models for the flows. These models have also been used to aid in the decisionanalysis process to determine the system-wide effects of potential intervention

\section{Literature review}

Sustainability goals are being designed to estimate the product performance, and to present the feedback required to improve product design. The mentioned goals are generally surrounds by three factors: ecology, society and economics. To enter these factors into the product design, it will be identified that whether the customers value such factors in their purchasing 
decisions or not. Consumer preferences for environmentally, socially and environmentally sustainable products have been quantified in the previous studies.

A general tool for enhancing these effects is to make transparency which may allow customers to make more informed decisions. So the present study, attempt to consider a fully cognitive structure that clearly visualizes the sustainability elements and their corresponding influencing factors. Hence, this study attempted to analyze factors of sustainable design in a dynamic manner through the hybrid method of FCM, CA, and SD.

Ferreira et al., (2017) studied sustainability factors in the banking industry through a combination of FCM and SD approaches. The main goal of their study was to develop an easily understood model to help decision makers analyze the dynamics of the cause-and-effect relationships between factors of sustainable product and long term scenarios.

Jetter \& Sperry (2013) presented a novel approach for product planning which was based on FCM modeling. The results showed that the mentioned method can help planners to systematically understand, and evaluate stakeholder needs. They applied planning product concepts for renewable energy systems.

Vidal et al., (2015) considered an FCM method to apply technological evolutions for more environmentally friendly products. Their tool has been applied to the ceramic industry using data from a survey. Their results illustrated evolution trends of ceramic products emphasized on design process, geometry, and material were more environmentally friendly.

A great deal of research has been undertaken to identify the influencing factors for the sustainable design based on customer preferences. Sustainable product design can enhance the market share of manufacturers. CA is a popular method of market research that uncovers consumers' preferences. Reyes-Mercado \& Rajagopal, (2017) studied features such as price, lifespan, reliability, and quality for $\mathrm{CA}$ in the printer market. The results of their analysis showed that the reliability and quality are the main drivers in different market segments. Aydin \& Badurdeen, (2019) studied features such as price, type, printing capacity, demand cycle in the printers market. They developed an optimization model considering economic and environmental objectives to determine the designs and selling prices of products.

Kuzmanovic et al., (2019) studied features such as printing speed, double-sided printing, and production costs of printers for $\mathrm{CA}$ in the printer market. The results of their analysis gives useful information related to the customers' preferences.

Complex interactions between variables emphasize the importance of simulation studies and SD. Pereira et al., (2020) proposed a combined FCM and the SD approach to predict the effects of energy-change on the sustainability of small and medium-sized enterprises. Liu et al., (2019) studied the relationship between design and sustainability factors using a SD approach. The results illustrated the positive impact of a design factors on the sustainable development.

Alamerew \& Brissaud, (2018), studied the interactions of sustainability through SD modeling with the aim of evaluating recovery strategies. Besides, a case study on electrical equipment was considered to validate the proposed model. Further simulation tools could also be applied to examine the relationship between different factors. In a study by Asif et al., (2016), the interactions of sustainability and design factors were showed using a multi-method simulation model of SD and agent-based principles.

According to mentioned literature, there have been comparatively few studies that investigate the presented approach in this paper, so the approach contributes to the literature on design and sustainability science. This study attempted to explore the relationship between various factors by using FCM, CA, and SD approaches. Through such a method, designers can change the variables of the models to create diverse scenarios. From the point of view of product design considering such a method for the products is interesting. Table 1 shows a classification of literature based on the used methods. The features related to the present study are presented in the last row of the table. 
Table 1. Summary of related literature.

\begin{tabular}{|c|c|c|c|c|c|c|}
\hline \multirow[b]{2}{*}{ Reference } & \multicolumn{3}{|c|}{$\begin{array}{c}\text { Sustainability } \\
\text { factors }\end{array}$} & \multirow[b]{2}{*}{ Product design factors } & \multirow[b]{2}{*}{ Industry } & \multirow[b]{2}{*}{ Method } \\
\hline & $\begin{array}{l}\tilde{0} \\
.00 \\
0 \\
0 \\
0 \\
1\end{array}$ & $\begin{array}{l}\bar{\pi} \\
\frac{\pi}{8} \\
0\end{array}$ & 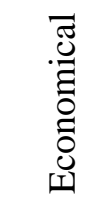 & & & \\
\hline $\begin{array}{c}\text { Aydin \& Badurdeen, } \\
\text { (2019) }\end{array}$ & $\checkmark$ & - & $\checkmark$ & $\begin{array}{c}\text { Price, Type, Printing } \\
\text { capacity, Demand cycle, } \\
\text { and Product return rate }\end{array}$ & $\begin{array}{l}\text { Printing } \\
\text { cartridge }\end{array}$ & $\begin{array}{l}\text { Optimization } \\
\text { model }\end{array}$ \\
\hline $\begin{array}{l}\text { Reyes-Mercado and } \\
\text { Rajagopal, (2017) }\end{array}$ & - & - & - & $\begin{array}{c}\text { Price, Lifespan, } \\
\text { Reliability, and Quality }\end{array}$ & $\begin{array}{l}\text { Printing } \\
\text { cartridge }\end{array}$ & CA \\
\hline $\begin{array}{l}\text { Kuzmanovic et al., } \\
\text { (2019) }\end{array}$ & & & & $\begin{array}{c}\text { Operation speed, } \\
\text { Double-sided printing, } \\
\text { and Production costs }\end{array}$ & Printer & CA \\
\hline $\begin{array}{c}\text { Alamerew \& } \\
\text { Brissaud, (2018), }\end{array}$ & $\checkmark$ & - & - & - & $\begin{array}{l}\text { Electrical } \\
\text { equipment }\end{array}$ & SD \\
\hline Asif et al., (2016) & $\checkmark$ & - & $\checkmark$ & $\begin{array}{l}\text { Price, Lifespan, recovery } \\
\text { rate }\end{array}$ & - & $\begin{array}{c}\text { Agent Based } \\
\text { and } \\
\text { SD }\end{array}$ \\
\hline Pereira et al.,(2020) & $\checkmark$ & - & $\checkmark$ & Type of energy & - & FCM and SD \\
\hline Ferreira et al., (2017) & $\checkmark$ & $\checkmark$ & $\checkmark$ & - & Banking & FCM and SD \\
\hline $\begin{array}{l}\text { Jetter \& Sperry } \\
\quad(2013)\end{array}$ & $\checkmark$ & - & - & - & $\begin{array}{l}\text { Renewable } \\
\text { energy } \\
\text { systems }\end{array}$ & FCM \\
\hline Vidal et al., (2015) & $\checkmark$ & - & - & $\begin{array}{l}\text { Design process, } \\
\text { Geometry, and Material }\end{array}$ & Ceramic & $\mathrm{FCM}$ \\
\hline Liu et al., (2019) & $\checkmark$ & - & - & - & Pilot study & SD \\
\hline This research & $\checkmark$ & $\checkmark$ & $\checkmark$ & $\begin{array}{l}\text { Product attributes, Price, } \\
\text { Lifespan, Environmental } \\
\text { effects, Reliability, } \\
\text { Transparency, and } \\
\text { Advertising }\end{array}$ & Printer & $\begin{array}{l}\text { CA, FCM, } \\
\text { and SD }\end{array}$ \\
\hline
\end{tabular}




\section{PROBLEM DESCRIPTION}

In this paper, we show how FCM, CA, and SD modelling can determine and create the cause-and-effect relationships at the stage of product design over a given planning horizon based on some discussions. FCM, CA, and SD approaches identified three areas of concern, namely: (1) Environmental impacts; (2) Social impacts; and (2) Economic impacts. In respect of the cognitive mapping techniques, this approach was created on discussions with the engineers. The first discussion comprised three steps, namely: (1) identifying factors of printer product; (2) creating clusters of factors; and (3) categorizing the factors based on the importance degree within each cluster. Remarkably, all the information which considered to build a collective cognitive map are according to the Decision Explorer software.

After the cognitive map was built, a second discussion was created to identify initial data required in the SD. Indeed, $\mathrm{CA}$ was conducted to attain more reliable outcomes based on customers' preferences. The total outputs of the CA method are price, reliability, transparency, environmental effects, and advertising factors. Finally, in order to develop an FCM, a third discussion was created and at the end of it, all the cause-and effect relationships had been clarified, and this clarification was the beginning point for a dynamic analysis of factors of printer product. This analysis allowed for the examination of the long-term outcomes of causeand-effect relationships. By mapping the relationships, designers could increase comprehending of the effects of their decisions. The details of the proposed hybrid method are described for a printer as a case study in the following sections. To describe the problem, a symbols list is presented in Table 2 .

\section{Fuzzy cognitive mapping}

Three major "Sustainability factors" have been considered in this model. These are: product's environmental impacts, social impacts, economic impacts (Rao et al., 2004) (see Figure 2). According to (De Silva et al., 2009), each of these factors was analyzed with quantified influencing factors. With the introduction of the above three sustainability elements and their influencing factors, a new framework can be provided to estimate the relationship of quantified factors with the sustainability created into a product at the design stage. Remarkably, all the information which applied to create a collective cognitive map are based on the Decision Explorer software. This map, is shown in Figure 1. 


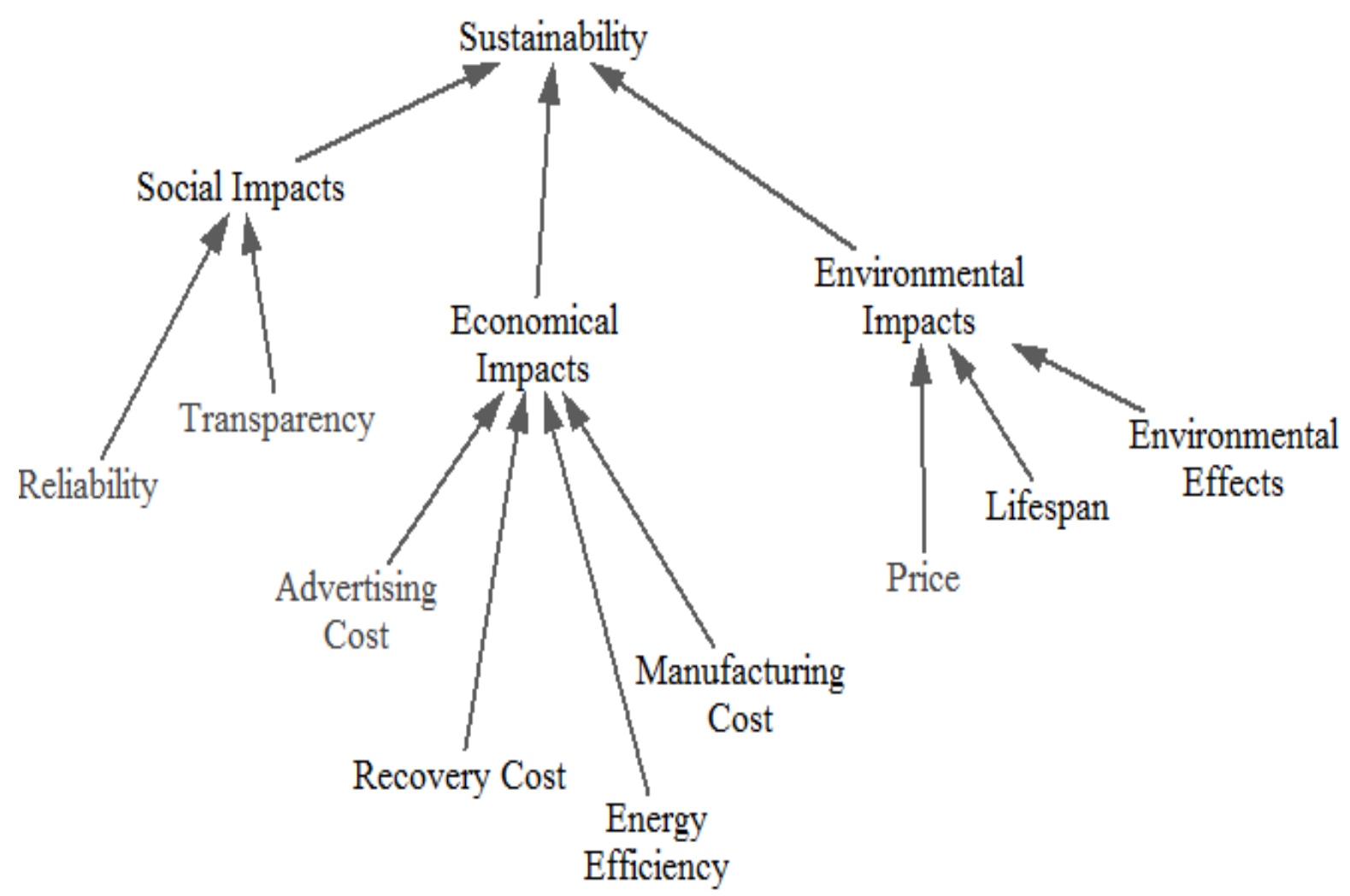

Figure 1 Collective cognitive map.

Table 2 Symbols list

\begin{tabular}{|l|l|}
\hline Parameters: & Estimated market size, \\
\hline$Q$ & Manufacturing costs of a product, \\
\hline$K$ & Total utility of the purchasing another product, \\
\hline$k a, k b, k c$ & Constant part-worth utility estimates for a product. \\
\hline \multicolumn{2}{|l|}{ Functions: } \\
\hline$U(u a, u b, u c, u d, u e)$ & Total utility for a given product, \\
\hline$u a(p r)$ & Part-worth utility estimates for a product price, \\
\hline$u b(E)$ & $\begin{array}{l}\text { Part-worth utility estimates for environmental impacts of a } \\
\text { product, }\end{array}$ \\
\hline$u c(R)$ & Part-worth utility estimates for a product reliability, \\
\hline$u d(T)$ & Part-worth utility estimates for a product transparency, \\
\hline$u e(A)$ & Part-worth utility estimates for a product advertising, \\
\hline $\operatorname{Prob}(U)$ & Probability of a consumer purchasing a product with utility $U$, \\
\hline$D(p r, E, R, T . A)$ & Demand function, \\
\hline$\pi(p r, E, R, T, A)$ & Profit function. \\
\hline \multicolumn{2}{|l}{} \\
\hline $\operatorname{Decisions}$ Variables: & \\
\hline$a_{0}, \ldots, a_{11}$ & Coefficients of the quadratic polynomial functions, \\
\hline$p r$ & Price of a product, \\
\hline$E$ & Environmental impacts of a product, \\
\hline
\end{tabular}




\begin{tabular}{|l|l|}
\hline$R$ & Reliability of a product, \\
\hline$T$ & Transparency of a product, \\
\hline$A$ & Advertising of a product. \\
\hline
\end{tabular}

\section{Conjoint analysis}

CA is conducted to capture consumer preferences for a product by estimating the part-worth utilities for each level of product attributes (Chen et al., 2012). It is to be noted that the CA model is an important part of the tool but detailing the logics of the CA is not within the scope of this paper.

\section{Formulation of the profit function}

The optimization formulation can be derived from Equation (2), which price pr is a variable; demand function $D$ is a function of price $p r$, reliability $R$, environmental effects $E$, transparency $T$, and advertising $A$. Hence, the profit function can be optimized based on five variables of $p r, E R, A$, and $T$ by following:

$$
\max _{p r, E, R, T, A} \pi=D(p r, E, R, T, A) \cdot(p r-C)
$$

To calculate $D$, the results of the CA allows for part-worth estimates. The CA provides a part-worth utility estimation for each level of each attribute, where the total utility of a product can be calculated by summing the part-worth utility estimates for all of that product's attributes. Since some product attributes are continuous in the optimization, and the CA gives discrete estimates for them, a curve fitting technique is applied to calculate part worth utility values (Chen et al., 2012). Further product attributes which are the outside of the study scope, can be considered constant. The calculation of total utility is illustrated in Equation (3) as follows:

$$
U=u a+u b+u c+u d+u e+k a+k b+k c
$$

where $U$ is the total utility for a given product, $u a, u b, u c, u d$, and $u e$ are the part-worth utility estimates which are variable, and $k a, k b$, and $k c$ are the part-worth utility estimates which are constant. The calculation of the variable part-worth utilities are illustrated as follows:

$$
\begin{aligned}
& u a=a_{0}+a_{1} p r+a_{2} p r^{2}, \\
& u b=a_{3}+a_{4} E+a_{5} E^{2}, \\
& u c=a_{6}+a_{7} R+a_{8} R^{2}, \\
& u d=a_{9}+a_{10} T+a_{11} T^{2}, \\
& u e=a_{9}+a_{10} A+a_{11} A^{2},
\end{aligned}
$$

In the above equations, the values of $a_{0}, \ldots, a_{11}$ are the coefficients of the quadratic polynomial functions; and $p r, E, R, T$, and $A$ are continuous attributes of the product. The probability of a consumer purchasing a product with utility $U$ is calculated using:

$$
\operatorname{Prob}(U)=\frac{e^{(U)}}{e^{(U)}+e^{(K)}}
$$


where $K$ is the utility of the purchasing another product on the market, and is set as constant, due to a lack of information associated with that product. Ultimately, $D$ is calculated by multiplying Prob by the size of market $Q$.

\section{System dynamics}

Different equations implemented in the SD are based on the key characteristics of FCMs and $\mathrm{SD}$, in which the value of a variable equals the value of the sum of all its cause-and-effect relationships. Besides, in regard to the clusters, an integral aggregation function of the sum of all their concepts' causality was applied, divided by 100, to scale the model appropriately. A logarithmic function of the sum of all clusters' values was also used to fix the value of the head variable and ensure the model was properly scaled. Also, regarding the variable of printer product, an integral function of the value of the head variable was considered to keep the model scale. Ultimately, a stock-flow diagram based on the Vensim software was portrayed in Figure 2.

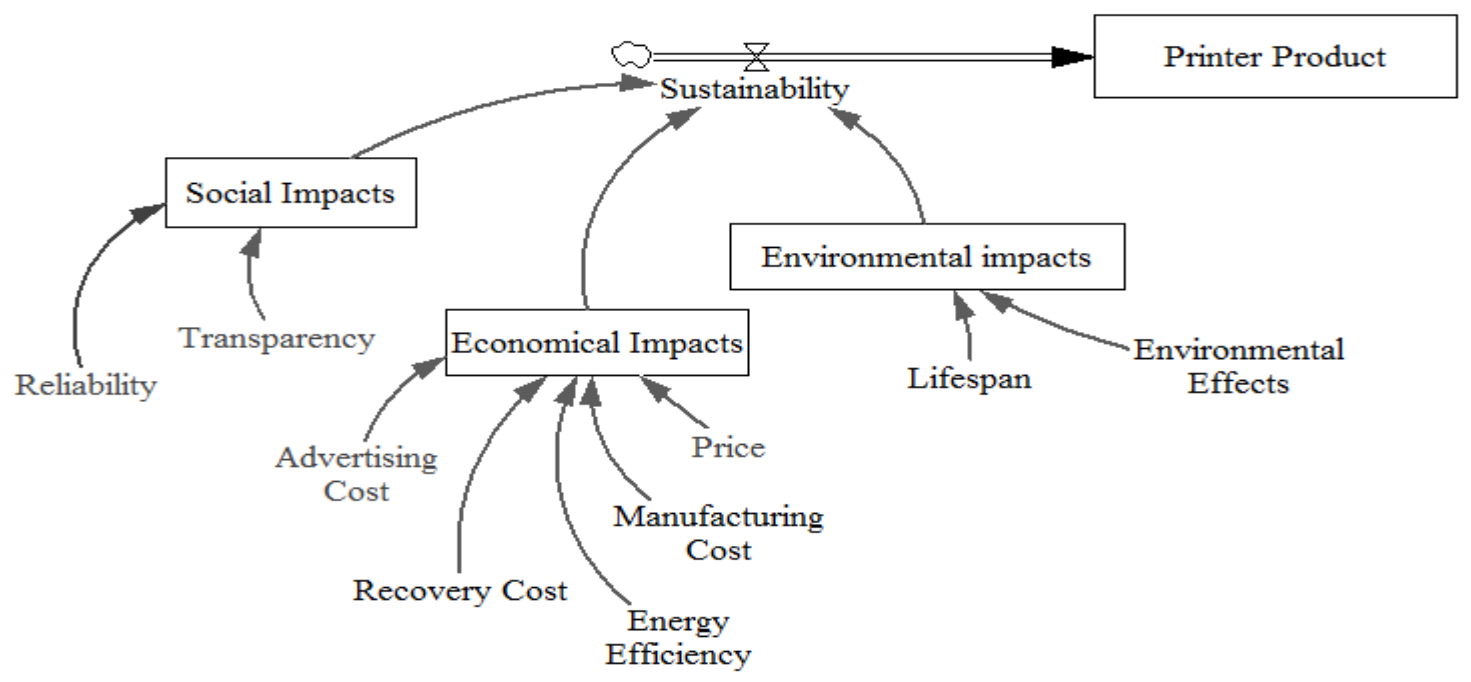

Figure 2 Stock and flow diagram of dynamics

\section{CASE STUDY}

The proposed methodology was applied in the design of a printer case. The main objective of the previously described approach, is to determine the optimal price, reliability, environmental effects, transparency, and advertising cost that will improve the product's sustainability. To estimate these optimal values, first, we surveyed Iran in an attempt to capture customer preferences about the printer. In this survey, many respondents answered questions about product attributes to evaluate the relationship of price, reliability, environmental effects, transparency, and advertising cost with profit optimization. Then, to assess consumer preferences for a product, the part-worth utility model was used for each level of product attribute. Respondents were asked to assign a score from 1 (very unfavorable) to 5 (very desirable) to each profile, taking into account several characteristics of each attribute in the analysis. The questionnaire was designed online and sent randomly to some customers.

\section{Conjoint analysis for printer}

In this study, eight attributes of the printer were determined to conduct CA. Data were gathered via online surveys. For this purpose, printer buyers in different cities of Iran answered 
questions about printers' features, and the results were applied for the construction of the demand function. The survey was performed online on 240 respondents who had the experience of using printer. Levels of price, recoverability, reliability, transparency, and advertising cost were set discretely.

These prices were estimated in the range of $\$ 4, \$ 15$, and $\$ 30$, reliability levels were set at three levels (20, 40, and 90 percentages), transparency levels were set at three levels (40,60, and 90 percentages), and ultimately, advertising cost levels were set at three levels $(100,120$, and 150 dollars). Since information on environmental effects not widely available in the specifications of printer on the market, another attribute was considered to exhibit this attribute. Based on this, the recoverability attribute was determined as important, which should be illustrated at three discrete levels. Thus, for each printer option, its recoverability attribute was set at three levels $(0,35$, and 70$)$. Ultimately, the user's preferences for the recoverability attribute were gathered and the part-worth utility of each attribute was determined. In the optimization model, which will be analyzed in the following sections, the recovery attribute is interpreted as environmental effects and rated on a scale of 0 to 100.

Further attributes in the choice scenarios include printing capacity, type of printer, and lifespan. These attributes are not directly in respect to the research goals, but since they are part of a printer purchasing decision and may help estimate the tastes of respondents, they were accounted for in the CA. Discrete values of printing capacity of printers based on the market were set at 5000, and 20,000. The quality of printer, including low and high, and finally, the lifespan feature, including 5 years and 8 years, were specified. Eight important product attributes and their corresponding levels, which were defined based on market information, are shown in Table 3. The latter three attributes, including printing capacity, type of printer, and lifespan, are also assumed to be constant.

Table 3 Product attributes and attribute levels of computer

\begin{tabular}{cccc}
\hline Attributes & Level 1 & Level 2 & Level 3 \\
\hline Price & 4 & 15 & 30 \\
\hline Recoverability & 0 & 35 & 70 \\
\hline Reliability & 20 & 40 & 90 \\
\hline Transparency & 40 & 60 & 90 \\
\hline Advertising cost & 100 & 120 & 150 \\
\hline Printing capacity & 5000 & 20,000 & - \\
\hline Quality of printer & Low & High & - \\
\hline Lifespan & 5 & 8 & - \\
\hline
\end{tabular}

\section{Optimization results}

Design optimization was performed, which fixed values are assumed for printing capacity, type of printer, and lifespan regarding neutral levels of those attributes so that the part-worth utility corresponding with them is set to zero. For further attributes, the part-worth utility values are estimated as follows:

$$
\begin{gathered}
u a=1.122-1.2 \times 10^{-5} p r-2.3 \times 10^{-5}(p r)^{2} \\
u b=0.522-8.2 \times 10^{-5} E-3.63 \times 10^{-7}(E)^{2} \\
u c=3.82-8.015 \times 10^{-4} R-3.536 \times 10^{-5}(R)^{2} \\
u d=0.22-4.2 \times 10^{-5} T-1.63 \times 10^{-7}(T)^{2} \\
u e=0.82-5.015 \times 10^{-2} A-2.506 \times 10^{-3}(A)^{2}
\end{gathered}
$$


Then, based on the size of the market which equals $24,000,000$, the quantity demanded is estimated. Finally, the results of solving the optimization problem for the printer market in Iran are presented in Table 4.

Table 4 Optimization results of the printer.

\begin{tabular}{ccc}
\hline Decision Variables & Value & Units \\
\hline $\boldsymbol{p} \boldsymbol{r}$ & 25.00 & Dollar \\
$\boldsymbol{R}$ & 65 & Percentage \\
\hline $\boldsymbol{E}$ & 10000 & Dollar \\
\hline $\boldsymbol{T}$ & 67 & Percentage \\
\hline $\boldsymbol{A}$ & 158 & Dollar \\
\hline $\boldsymbol{M} \boldsymbol{S}$ & 5.11 & Percentage \\
\hline $\boldsymbol{\pi}$ & $110 \times 10^{6}$ & Dollar \\
\hline
\end{tabular}

\section{System dynamics simulation results}

The value of initial performance of the clusters, head variable, and printer product are exhibited in Table 5. In this study, several simulations were conducted to test the proposed model.

Table 5 Initial performances of clusters, head variable and printer product.

\begin{tabular}{cc}
\hline Initial Performance & Values \\
\hline Environmental impacts & 15.12000 \\
\hline Social impacts & 14.18000 \\
\hline Economic impacts & 10.26097 \\
\hline Head variable & 4.70255 \\
\hline Printer product & 3.27018 \\
\hline
\end{tabular}

The inter-cluster analysis started with tuning the values of variables of the clusters to determine the outcomes for printer product. In the Scenario 1, two simulations were conducted: (1) Simulation 1, with a -0.2 change in the values of the clusters; and (2) Simulation 2, with a -0.7 change in the values of each cluster. The initial cause-and-effect relationships are quantified between the head variable and clusters, and those weights are placed in Table 6. The results for the head variable are presented in Table 7. It is obvious from Table 7, Simulations 1 and 2 have a negative impact on the performance regarding to the head variable. These results also show that Simulation 1 has a less negative effect than Simulation 2 does, and this effect correlated with the simulations' initial values. Next, intracluster analysis, exhibited the changes in each one of the clusters' criteria, based on the following tables.

Table 6 Weights of cause-and-effect relationships between head variable and clusters.

\begin{tabular}{cc}
\hline Determinant & Weight of Relationship \\
\hline Environmental impacts & 0.90 \\
\hline Social impacts & 1 \\
\hline Economic impacts & 0.90 \\
\hline
\end{tabular}

Table 7 Various values of sustainability in each simulation 1 and 2.

\begin{tabular}{ccc}
\hline Determinant & Simulation 1 & Simulation 2 \\
\hline Sustainability & -0.01113 & -0.02738 \\
\hline
\end{tabular}


Table 8 Various values in Simulations 3 and 4 for Scenario 2.

\begin{tabular}{cccc}
\hline Determinant & $\begin{array}{c}\text { Weight of } \\
\text { Relationship }\end{array}$ & Simulation 5 & Simulation 6 \\
\hline $\begin{array}{c}\text { Environmental } \\
\text { effects }\end{array}$ & -0.85 & -0.2 & -0.4 \\
\hline Lifespan & 1 & -0.5 & -0.9 \\
\hline
\end{tabular}

Table 9 Various values in Simulations 5 and 6 for Scenario 3.

\begin{tabular}{cccc}
\hline Determinant & $\begin{array}{c}\text { Weight of } \\
\text { Relationship }\end{array}$ & Simulation 5 & Simulation 6 \\
\hline Transparency & 0.90 & -0.1 & -0.2 \\
\hline Reliability & 0.90 & -0.3 & -0.6 \\
\hline
\end{tabular}

Table 10 Various values in Simulations 7 and 8 for Scenario 4.

\begin{tabular}{cccc}
\hline Determinant & $\begin{array}{c}\text { Weight of } \\
\text { Relationship }\end{array}$ & Simulation 7 & Simulation 8 \\
\hline Price & -0.90 & -0.4 & -0.8 \\
\hline Advertising cost & -0.90 & -0.3 & -0.6 \\
\hline Manufacturing cost & -0.90 & -0.2 & -0.7 \\
\hline Recovery cost & -0.80 & -0.3 & -0.5 \\
\hline Energy efficiency & 1 & -0.1 & -0.2 \\
\hline
\end{tabular}

Tables 8-10 linked with the clusters and their related scenarios. The long-term results for the clusters stemming from the changes conducted above are revealed in Table 11. It is obvious from Table 11, Simulation 3 has a less negative long-term impact on the performance of the Environmental impacts cluster compared with Simulation 4, because the simulation values illustrated in Table 8 are less negative. We also demonstrate that Simulations 5 and 6 have negative long-term effects on the performance of the Social impacts.

Table 11 Long-term changes in clusters' values for each simulation

\begin{tabular}{|c|c|c|}
\hline $\begin{array}{c}\text { Cluster } \\
\text { Environmental impacts }\end{array}$ & $\begin{array}{c}\text { Simulation } 3 \\
-1.20\end{array}$ & $\begin{array}{c}\text { Simulation } 4 \\
-2.60\end{array}$ \\
\hline $\begin{array}{c}\text { Cluster } \\
\text { Social impacts }\end{array}$ & $\begin{array}{c}\text { Simulation } 5 \\
-2.80\end{array}$ & $\begin{array}{c}\text { Simulation } 6 \\
-3.20\end{array}$ \\
\hline $\begin{array}{c}\text { Cluster } \\
\text { Economic impacts }\end{array}$ & $\begin{array}{c}\text { Simulation } 7 \\
-3.40\end{array}$ & $\begin{array}{c}\text { Simulation } 8 \\
-3.60\end{array}$ \\
\hline \multicolumn{3}{|c|}{$\begin{array}{l}\text { Due to the simulation values illustrated in Table } 9 \text { are also more negative in Simulation } 6 \text {, } \\
\text { Simulation } 6 \text { has a much stronger negative effect. The results for the performance of the } \\
\text { Economic impacts cluster related to changes in the decision criteria, as located in Table } 10 \text { are } \\
\text { also obvious in Table } 11 \text {. The long-term results are less negative in Simulation } 7 \text { because, } \\
\text { again, the simulation values illustrated in Table } 11 \text { are less negative compared with } \\
\text { Simulation } 8 \text {. Figure } 3 \text {, presents the long-term behavior of the printer product and head } \\
\text { variable for Simulations } 6 \text { to } 8 \text {. In addition, the long-term performance of the clusters, can be } \\
\text { found in Figure } 4 \text {. }\end{array}$} \\
\hline
\end{tabular}




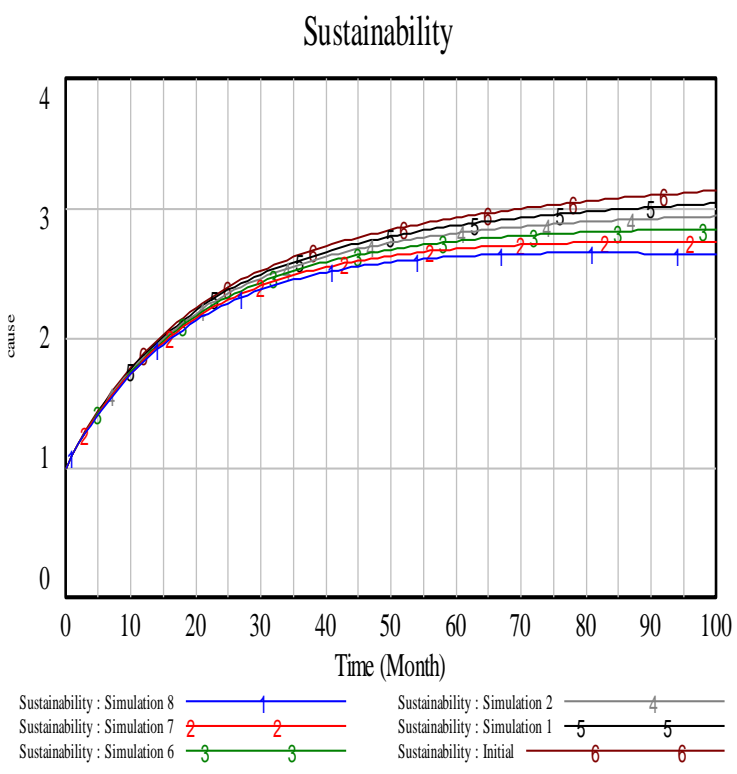

(a)

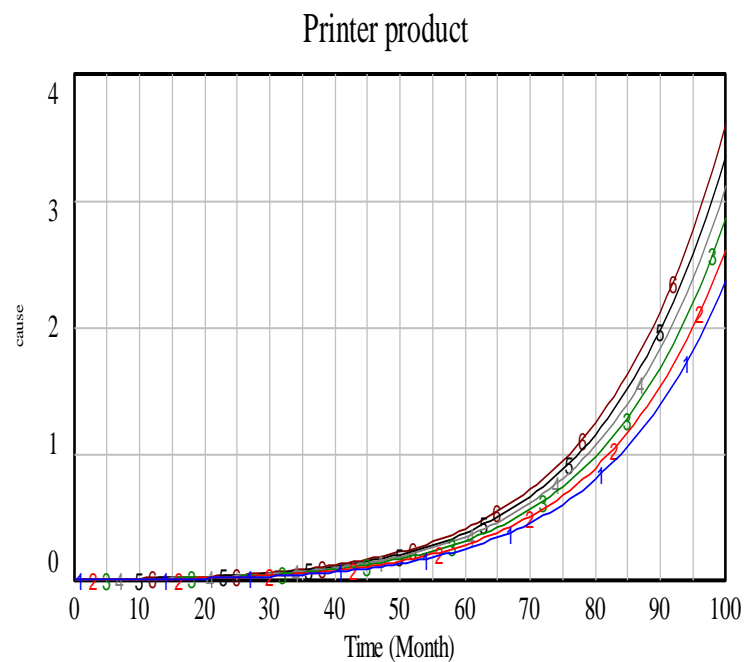

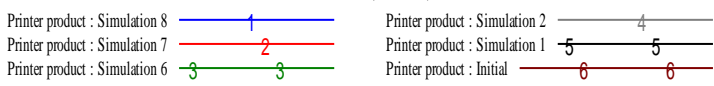

(b)

Figure 3 Long-term performance of head variable and printer product for their simulations.

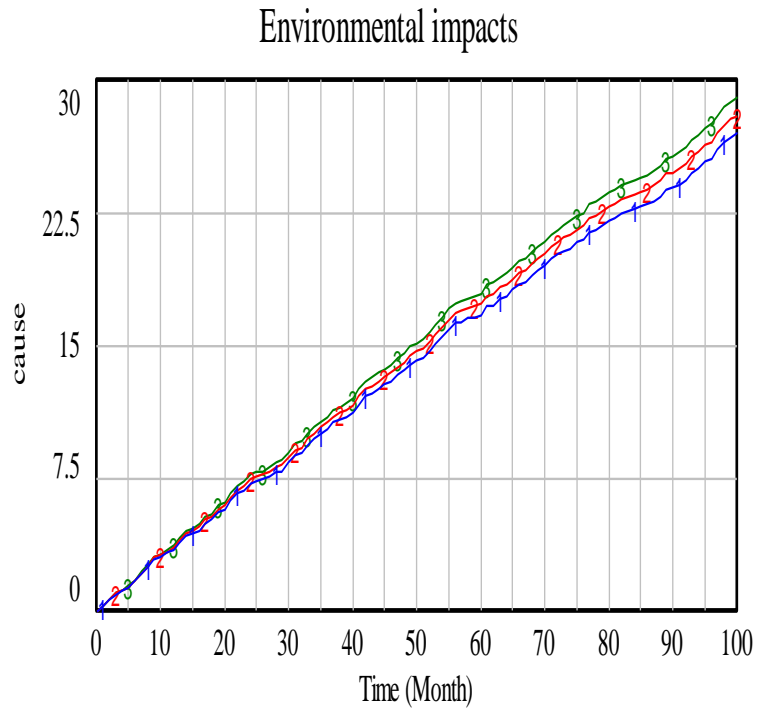

Environmental impacts: Simulation $4+, 1,1,1,1,1,+$ Environmental impacts: Simulation $3 \begin{array}{lllllllll}3 & 2 & 2 & 2 & 2 & 2 & 2 & 2 & 2\end{array}$ Environmental impacts: Initial $\begin{aligned} & 3 \\ & 3\end{aligned}$

(a)

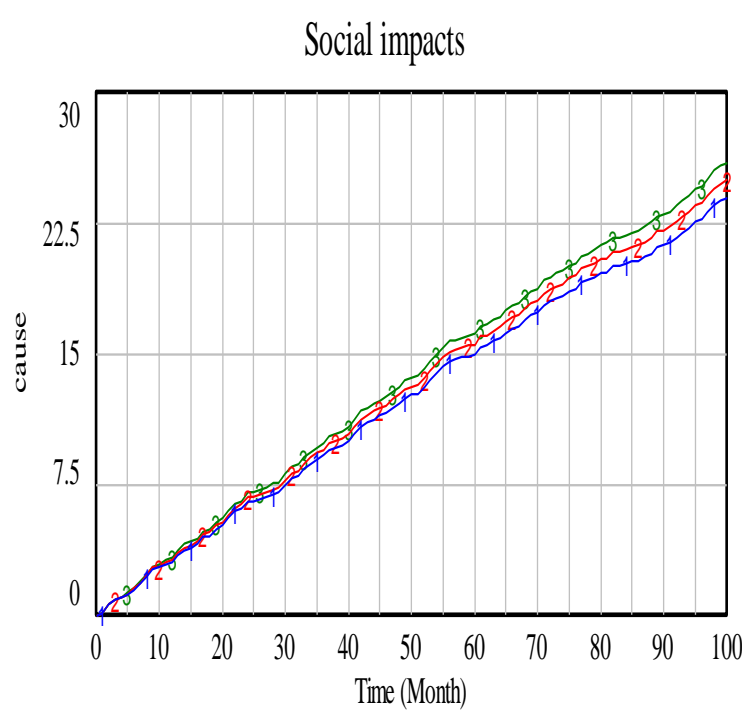

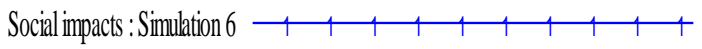
Social impacts: Simulation $5 \begin{array}{lllllllllll}2 & 2 & 2 & 2 & 2 & 2 & 2 & 2 & 2 & 2 & 2\end{array}$ Social impacts : Initial $\begin{array}{lllllllllll}3 & 3 & 3 & 3 & 3 & 3 & 3 & 3 & 3 & 3 & 3\end{array}$

(b) 


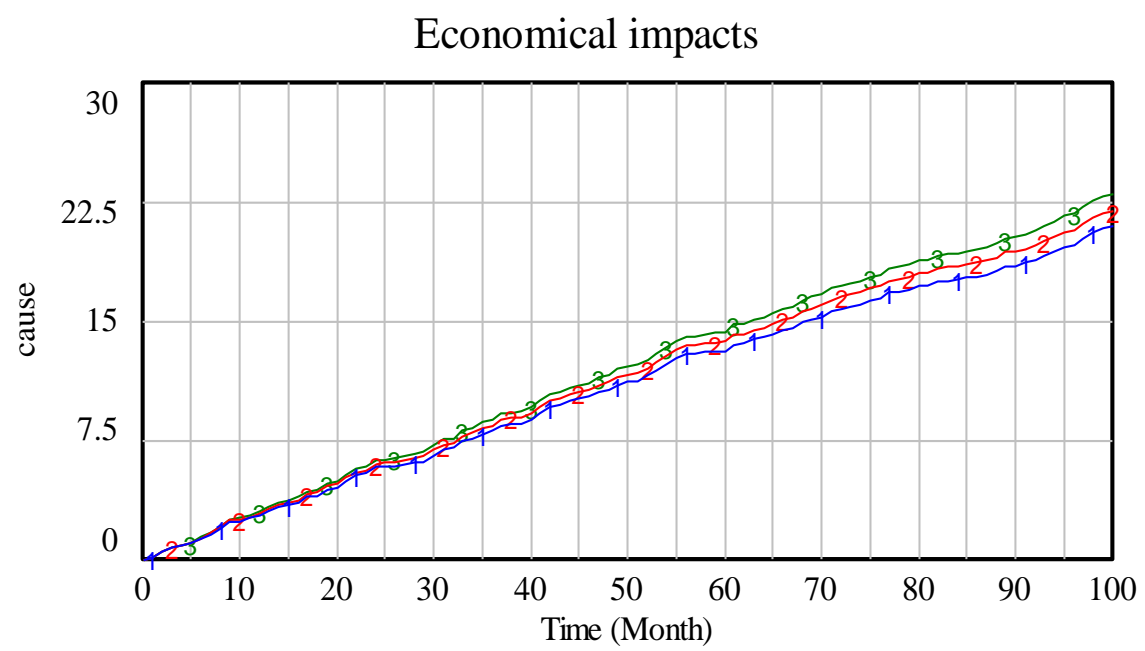

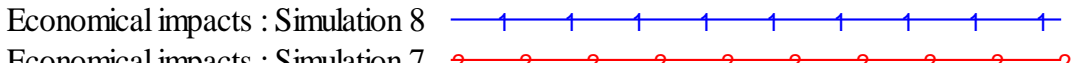

$\begin{array}{llllllllllll}\text { Economical impacts : Simulation } 7 & 2 & 2 & 2 & 2 & 2 & 2 & 2 & 2 & 2 \\ \text { Economical impacts : Initial }\end{array}$

(c)

Figure 4 Long-term performance of clusters for their simulations.

Therefore, Figures 3 and 4 exemplify the long-term behavior for all simulations conducted in this study. The printer product stakeholders must comprehend these changes in order to engage in greater accuracy decision making processes. All these factors can impact the evolution of sustainable printer product over time, so engineers need to analyze and handle continuously possible variations of the presented model and stimulate sustainable attitudes in their companies.

\section{CONCLUSION AND FUTURE RESEARCH}

This study proposed a hybrid model for the design process of products such as printer that incorporate variables, including environmental impacts, social impacts, and economic impacts. The hybrid approach presented in this paper allows designers to consider a number of variables that influence printer product and the cause-and-effect relationships in the FCM. Through such a model, everyone can alter variables of the models to build diverse scenarios. The designers must comprehend the effect of changes in order to make greater informed decisions. In this approach, first, the optimal values of the date required were identified by $\mathrm{CA}$ in terms of the demand and profit functions. These optimal values are inserted to the SD model to map the trades off between variables and evaluate the changes that can affect printer product. Most of the data required to run SD are extracted from the CA related to the printer case, and only few data, are extracted from the (Rao et al., 2004).

The above approach only considers three factors affecting printer product, and further factors such as manufacturability, and Functionality are be neglected. It is recommended to incorporate more detailed factors in the model, and to identify how these decisions can affect the product. Researchers can also utilize further uncertainties such as robust, possibilistic, and possible techniques as described by (Lotfi et al., 2017, Lotfi et al., 2019, Lotfi et al., 2020(a) \& Lotfi et al., 2020(b)). 


\section{REFERENCES}

Abramova, N. 2016. The cognitive approach to the problem of identification validity in cognitive mapping. IFAC-PapersOnLine 49(12): 586-591.

Alamerew, Y. A. \& Brissaud, D. 2018. Modelling and assessment of product recovery strategies through systems dynamics. Procedia CIRP 69: 822-826.

Asif, F. M., Lieder, M. \& Rashid, A. 2016. Multi-method simulation based tool to evaluate economic and environmental performance of circular product systems. Journal of Cleaner Production 139: 12611281.

Aydin, R. \& Badurdeen, F. 2019. Sustainable product line design considering a multi-lifecycle approach. Resources, Conservation and Recycling 149: 727-737.

Chen, W., Hoyle, C. \& Wassenaar, H. J. 2012. Decision-based design: Integrating consumer preferences into engineering design. Springer Science \& Business Media.

De Silva, N., Jawahir, I. S., Dillon Jr, O. \& Russell, M. (2009). A new comprehensive methodology for the evaluation of product sustainability at the design and development stage of consumer electronic products. International Journal of Sustainable Manufacturing 1(3): 251-264.

Ferreira, F. A., Ferreira, J. J., Fernandes, C. I., Meidutė-Kavaliauskienė, I., \& Jalali, M. S. 2017. Enhancing knowledge and strategic planning of bank customer loyalty using fuzzy cognitive maps. Technological and Economic Development of Economy 23(6): 860-876.

Forrester, J. W. 1958. Industrial Dynamics. A major breakthrough for decision makers. Harvard business review 36(4): 37-66.

Jetter, A. J. \& Sperry, R. C. 2013. Fuzzy cognitive maps for product planning: using stakeholder knowledge to achieve corporate responsibility. In 2013 46th Hawaii International Conference on System Sciences: 925-934.

Kosko, B. 1986. Fuzzy cognitive maps. Int J Man Mach Stud 24(1): 65-75.

Kuzmanovic, M., Martic, M. \& Vujosevic, M. 2019. Designing a profit-maximizing product line for heterogeneous market. Tehnički vjesnik 26(6): 1562-1569.

Liu, L., Hsu, Y. \& Lin, J. 2019. Sustainable development analysis of design and manufacturing integration: A system dynamics approach. Cogent Engineering 6(1): 1682775.

Lotfi, R., Mehrjerdi, Y. Z., \& Mardani, N. 2017. A multi-objective and multi-product advertising billboard location model with attraction factor mathematical modeling and solutions. International Journal of Applied Logistics 7(1): 64-86.

Lotfi, R., Mehrjerdi, Y. Z., Pishvaee, M. S., Sadeghieh, A. \& Weber, G. W. 2019. A robust optimization model for sustainable and resilient closed-loop supply chain network design considering conditional value at risk. Numerical Algebra, Control \& Optimization 11(2): 221-253

Lotfi, R., Weber, G. W., Sajadifar, S. M. \& Mardani, N. 2020(a). Interdependent demand in the twoperiod newsvendor problem. Journal of Industrial \& Management Optimization 16(1): 117.140

Lotfi, R., Yadegari, Z., Hosseini, S. H., Khameneh, A. H., Tirkolaee, E. B. \& Weber, G. W. 2020(b). A robust time-cost-quality-energy-environment trade-off with resource-constrained in project management: a case study for a bridge construction project. Journal of Industrial \& Management Optimization. doi: 10.3934/jimo.2020158.

Pereira, I. P., Ferreira, F. A., Pereira, L. F., Govindan, K., Meidutė-Kavaliauskienė, I. \& Correia, R. J. 2020. A fuzzy cognitive mapping-system dynamics approach to energy-change impacts on the sustainability of small and medium-sized enterprises. Journal of Cleaner Production 256: 120154.

Papalambros, P. Y. \& Wilde, D. J. 2000. Principles of optimal design: modeling and computation. Cambridge university press.

Rao, N. U., Yuan, C. Y. \& Zhang, H. C. 2004. An economic model for end-of-life management of printed circuit boards. In IEEE International Symposium on Electronics and the Environmental : 5762.

Reyes-Mercado, P. \& Rajagopal. 2017. Dynamics of disruptive innovations in outperforming global brands: a study in Mexico. International Journal of Business Excellence 11(1): 1-15.

Vidal, R., Salmeron, J. L., Mena, A. \& Chulvi, V. 2015. Fuzzy Cognitive Map-based selection of TRIZ (Theory of Inventive Problem Solving) trends for eco-innovation of ceramic industry products. Journal of Cleaner Production 107: 202-214. 


\section{Response to Reviewer' Comments}

Title of the revised manuscript: A new optimization-simulation model considering sustainability factors in the product design

\section{Dear Professor, Ameer Al Haddad Editor in Chief of Journal of Engineering Research (JER)}

We authors are very thankful for the expressed opinions and requests of the respected reviewers. In fact, We took these comments very seriously and completely revised the manuscript accordingly to address the necessary added values to the new submission and to give to our paper a better appeal and realize higher standards. We have highlighted all the changes in yellow color in a new manuscript. We have also changed the title of manuscript to "A new optimization-simulation model considering sustainability factors in the product design", in the revised manuscript.

Best regards,

The authors

Response to Reviewers: It is suitable based on review comments.

\begin{tabular}{|l|l|}
\hline Request Revise & Response to Reviewers \\
\hline $\begin{array}{l}\text { 1. Please add lit. review table and add research } \\
\text { gap (please see and cite [1], [2], [3], [4]). }\end{array}$ & $\begin{array}{l}\text { We are thankful for valuable comments. Lit. Review } \\
\text { summarized in Table 1, and the research gap highlighted } \\
\text { in the revision. }\end{array}$ \\
\hline $\begin{array}{l}\text { 2. Please add notation table and define sets, } \\
\text { parameters, decision variables (please see and } \\
\text { cite [1], [2], [3], [4]). }\end{array}$ & $\begin{array}{l}\text { We added notation table and define parameters, decision } \\
\text { variables, and highlighted them, in the revised manuscript. }\end{array}$ \\
\hline $\begin{array}{l}\text { 3. For every formula draw a table without } \\
\text { border and column one for formula, column } \\
\text { two for indices and column three for numbers } \\
\text { (please see and cite [1], [2], [3], [4]). }\end{array}$ & $\begin{array}{l}\text { We drawed the tables as you mentioned, in the revised } \\
\text { manuscript. }\end{array}$ \\
\hline $\begin{array}{l}\text { 4. In conclusion please suggest fuzzy and } \\
\text { robust optimization for future research (please } \\
\text { see and cite [1], [2], [3], [4]). }\end{array}$ & $\begin{array}{l}\text { The mentioned references added as the future research } \\
\text { in conclusion section, in the revised manuscript. }\end{array}$ \\
\hline
\end{tabular}

Now, we authors are deeply indebted to the anonymous referees and express our deep thankfulness for being welcome to submit to you our entire revision, and we hope that the paper has reached the highest quality in every respect. 